\title{
Editorial: Volume 30 Issue 3
}

In this editorial we'd like to take the opportunity provided by the release of the 2014 Google Scholar Journal Metrics to explain the various journal metrics, how they are calculated and how AJET rates against other Educational Technology journals. Journal metrics broadly refer to the various measures of quality or impact of a journal, largely based on the number of articles published in the journal itself and citations in other journals to articles published in the journal. As well as being used to rank the journals themselves, metrics are often used as a proxy measure of the quality of articles in a particular journal, and thus individual researchers' publication lists. For example, it is common for researchers to refer to the impact factor of the journals in which they have published as part of grant applications.

The three most well known journal metric sources are the Thomson Routers Journal Citation Reports (previously known as the ISI Journal Citation Reports), Google Scholar Metrics, and Scopus Journal Analyser. Each of these sources includes a number of metrics or indices that use specific algorithms drawing on data within their own databases of journals, articles and citations. The following paragraphs explain the key metrics used by these sources.

The Journal Impact Factor is a measure of the average number of citations from articles published in the current year in any journal to articles published in the target journal in the past three or five years. The most commonly used metrics provided by the Journal Citation Reports (JCR) are the 5-year and 3-year Journal Impact Factors (see http://thomsonreuters.com/journal-citation-reports/). AJET's 5-year impact factor of 1.540 ranks it $41^{\text {st }}$ in the Education and Educational Research category and $6^{\text {th }}$ of Educational Technology journals in this category. Table 1 lists the top ten Educational Technology journals based on their most recent (2012) JCR 5-year impact factors.

Table 1. Journal Citation Report 2012 5-year impact factors for leading Educational Technology journals

\begin{tabular}{lc}
\hline Journal & $\begin{array}{c}\text { 5-year } \\
\text { Impact Factor }\end{array}$ \\
\hline Computers and Education & 3.305 \\
International Journal of Computer-Supported & 2.904 \\
Collaborative Learning & 2.205 \\
Language Learning and Technology & 2.095 \\
Journal of Computer Assisted Learning & 1.888 \\
British Journal of Educational Technology & 1.540 \\
Australasian Journal of Educational Technology & 1.522 \\
Educational Technology Research and Development & 1.505 \\
Educational Technology and Society & 1.491 \\
Interactive Learning Environments & 0.893 \\
IEEE Transactions on Learning Technologies & \\
\hline
\end{tabular}

Impact Factor is an index that can be sensitive to a small number of highly cited articles. In AJET's case there is a fairly even contribution from a range of articles to this figure. AJET's 2012 5-year impact factor of 1.540 was calculated using the 405 citations to articles out of the 263 published in AJET during the years 2007 to 2011. Of these 405 citations, 84 were to 8 AJET articles with between 9 and 22 citations with 163 articles contributing through at least 1 citation. This fairly even coverage of cited articles tends to make AJET less susceptible to major fluctuations in Impact Factor from year to year.

The journal metrics provided by Google Scholar are the h5-index and the h5-median (see http://scholar.google.com.au/intl/en/scholar/metrics.html). The h5-index is similar to the h-index used as a measure of an individual's publications and citations. Google define it as "the largest number $\mathrm{h}$ such that $\mathrm{h}$ articles published in 2009-2013 have at least h citations each”. For example AJET has an h5-index of 30 
because there are 30 articles published from 2009 to 2013 that have 30 or more citations. The h5-median is the median number of citations of the articles making up the h5-index. AJET's h5-median of 57 indicates that the median number of citations of the top 30 cited articles is 57 . AJET is ranked 8 th by h5index in the Educational Technology category. Table 2 lists the top 10 Educational Technology journals based on their h5-index, along with the h5-median for each.

Table 2. Google Scholar 2014 h5-index and h5-median for leading Educational Technology journals

\begin{tabular}{lcc}
\hline Journal & h5-index & h5-median \\
\hline Computers and Education & 81 & 116 \\
British Journal of Educational Technology & 44 & 63 \\
Educational Technology and Society & 39 & 59 \\
Journal of Computer Assisted Learning & 38 & 59 \\
The Internet and Higher Education & 35 & 57 \\
The International Review of Research in Open and & 34 & 54 \\
Distance Learning & 33 & 46 \\
Educational Technology Research and Development & 30 & 57 \\
Australasian Journal of Educational Technology & 27 & 36 \\
IEEE Transactions on Learning Technologies & 25 & 43 \\
International Journal of Computer-Supported & & \\
Collaborative Learning & & \\
\hline
\end{tabular}

A journal's h5-index is influenced primarily by the number of moderately cited articles and is unaffected by the number of citations of the top articles (e.g. if AJET's top 10 articles had an additional 1000 citations each this would not affect the h5-index). Journals that publish a larger number of articles have an advantage in h5-index calculations because it is based on the number of publications with citations above a threshold rather than the average number of citations per article. Computers and Education, for example, published over 250 articles in 2013 compared to AJET's 60.

Metrics provided by Scopus are the Source Normalized Impact per Paper (SNIP) and the SCImago Journal Rank (SJR) (see http://www.journalmetrics.com/). The SNIP is based on the average number of citations per article but with a weighting of citations based on the total number of citations in a subject field. This allows citations to be compared across subject fields. The SJR is also based on citations, but each citation is weighted according to the quality of the citing journal, based on the subject field, quality and reputation of the journal, and then normalised for differences in citation behaviour between subject fields. AJET's 2013 SNIP was 1.161 and its SJR was 0.953. The SNIP and SJR of some of the other leading Educational Technology journals in 2013 were Computers and Education (3.292 and 2.558), Internet and Higher Education (2.554 and 2.565), Journal of Computer Assisted Learning (2.469 and 2.144), Educational Technology Research and Development (2.080 and 1.785), British Journal of Educational Technology (1.709 and 1.523) and Educational Technology and Society (1.654 and 0.989).

In the paragraphs above we have tried to include a cross section of the most commonly used metrics to provide readers with a clearer understanding of some of the key measures of journal quality and impact. It is important to acknowledge that this is not a complete list of the full range of metrics available. For example, Thomson Routers and Scopus both provide some additional indices that we have not discussed. Similarly, we have not discussed the Eigenfactor index and the related Article Influence index which are explained and reported at http://eigenfactor.org, nor altmetrics, which are alternative metrics at either the article or journal level which take into account a wider range of data beyond citations, including article views, downloads and mentions in social media (see, for example, http://www.altmetric.com/).

Given the potential for journal metrics to influence authors and readers in publishing, reading and citing articles in a journal, an important question for journal editors is whether there is scope for strategic work focussing on increasing scores on the various metrics. A first step towards this might be developing an understanding of the way in which key characteristics of a journal impact on metrics. Such characteristics 
include the volume of articles published and the nature of articles published in terms of their topic focus, methodological approach or target readership. Increasing the volume of articles published is likely to increase the Google Scholar h5-index, but is not likely to increase the JCR impact factor, and could in fact result in a decrease in the impact factor if increasing the volume results in a larger number of weaker or less cited articles.

The question of whether there is a relationship between the types of articles published and the likelihood of citation is a complex one. One way to explore this would be to look at the characteristics of the most cited articles. Table 3 lists the most cited articles in AJET over the past five years and some of their characteristics. A rudimentary analysis of the characteristics of these articles would suggest that a number of them include comprehensive reviews or a body of prior work that has culminated in new theoretical contributions. Case studies of the applications of Mobile, Web 2.0 and collaborative learning technologies are also well represented, indicating that these have been topics of particular interest to readers during this period. A more systematic analysis of the characteristics of highly cited articles in the Educational Technology field could, for example, underpin editorial decisions about special issues or review guidelines, as a way of encouraging the publication of articles of most interest to readers and with high prospects of citation.

Table 3. Characteristics of the most cited articles in AJET over the past five years

\begin{tabular}{|c|c|c|c|}
\hline Article & $\begin{array}{l}\text { Number of } \\
\text { citations }\end{array}$ & Year & $\begin{array}{c}\text { Article } \\
\text { characteristics }\end{array}$ \\
\hline $\begin{array}{l}\text { Personalised and Self Regulated Learning in the Web } 2.0 \text { Era: } \\
\text { International Exemplars of Innovative Pedagogy Using Social } \\
\text { Software. } \\
\text { C McLoughlin, MJW Lee. AJET } 26(1), 28-43\end{array}$ & 161 & 2010 & $\begin{array}{l}\text { Review/ } \\
\text { commentary }\end{array}$ \\
\hline $\begin{array}{l}\text { A Review of Podcasting in Higher Education: Its Influence on the } \\
\text { Traditional Lecture. } \\
\text { O McGarr, AJET } 25 \text { (3), 309-321 }\end{array}$ & 136 & 2009 & Review \\
\hline $\begin{array}{l}\text { Learning about Problem Based Learning: Student Teachers } \\
\text { Integrating Technology, Pedagogy and Content Knowledge. } \\
\text { HJ So, B Kim, AJET } 25 \text { (1), 101-116 }\end{array}$ & 121 & 2009 & Case study \\
\hline $\begin{array}{l}\text { Smartphones Give You Wings: Pedagogical Affordances of } \\
\text { Mobile Web 2.0. } \\
\text { T Cochrane, R Bateman, AJET } 26 \text { (1), 1-14 }\end{array}$ & 114 & 2010 & $\begin{array}{l}\text { Theory/ } \\
\text { review }\end{array}$ \\
\hline $\begin{array}{l}\text { Using Wikis for Collaborative Learning: Assessing Collaboration } \\
\text { through Contribution. } \\
\text { T Judd, G Kennedy, S Cropper, AJET } 26 \text { (3), 341-354 }\end{array}$ & 108 & 2010 & Case study \\
\hline $\begin{array}{l}\text { "Cloudworks": Social Networking for Learning Design. } \\
\text { G Conole, J Culver, AJET } 25 \text { (5), 763-782 }\end{array}$ & 92 & 2009 & $\begin{array}{l}\text { Theory/ } \\
\text { technology }\end{array}$ \\
\hline $\begin{array}{l}\text { The Wiki Way of Learning. } \\
\text { A Ruth, L Houghton, AJET } 25 \text { (2), 135-152 }\end{array}$ & 83 & 2009 & $\begin{array}{l}\text { Case study/ } \\
\text { theory }\end{array}$ \\
\hline $\begin{array}{l}\text { Usability and Usefulness of eBooks on PPCs: How Students' } \\
\text { Opinions Vary over Time. } \\
\text { P Lam, SL Lam, J Lam, C McNaught, AJET } 25 \text { (1), 30-44 }\end{array}$ & 74 & 2009 & Case study \\
\hline $\begin{array}{l}\text { The Effects of Using a Wiki on Student Engagement and Learning } \\
\text { of Report Writing Skills in a University Statistics Course. } \\
\text { DL Neumann, M Hood, AJET } 25 \text { (3), 382-398 }\end{array}$ & 72 & 2009 & $\begin{array}{l}\text { Quasi } \\
\text { experimental } \\
\text { study }\end{array}$ \\
\hline $\begin{array}{l}\text { The Networked Student Model for Construction of Personal } \\
\text { Learning Environments: Balancing Teacher Control and Student } \\
\text { Autonomy. } \\
\text { W Drexler, AJET } 26 \text { (3), 369-385 }\end{array}$ & 69 & 2010 & $\begin{array}{l}\text { Case study/ } \\
\text { theory }\end{array}$ \\
\hline
\end{tabular}


Aside from adjusting editorial policies to encourage submission of articles that are likely to be cited, or creating special issues in areas likely to attract a wide readership, another approach to increasing scores on citation metrics that some editors have been known to adopt is asking authors to cite more articles from their journal as a condition of publication. The stated rationale for doing this can be that citation of articles from within the journal provides a clear indicator of the fit of an article to the journal. We have no plans to start expecting a minimum number of citations to AJET articles in submitted articles. However, we do acknowledge that citing a number of articles from AJET in your reference list does show that you are aware of the body of literature of interest to the readership of the journal and may help to make the case that your article will advance the field of educational technology in higher education.

Our overall editorial approach is to ensure that all articles published meet a rigorous standard of research and scholarship and fit within the focus and scope of the journal. We tend to keep the volume of articles published at the level needed to ensure timely publication of accepted articles, regardless of the effect on citation metrics. We do not believe that lowering the quality standards of AJET to increase the volume of publications would further the reputation of the journal. In general we feel that although metrics can be valuable in evaluating the performance of a journal they should not be the primary driver of editorial policy. Given the range of metrics and the quite different ways in which they are calculated, the best editorial approach is to maintain the quality of the journal and ensure that the articles we are publish are of interest to our readership. This approach should ensure that we maintain and continue to improve our performance against the existing metrics and against new metrics that emerge into the future.

We begin this issue with the best paper from 2013 ascilite conference by Bower, Kenney, Dalgarno, Lee and Kennedy. The paper outlines a series of case studies associated with blended synchronous learning designs, and details some of the issues encountered when implementing these designs in practice. The second paper in this issue by Ellis sheds light on the complex relationship between student inquiry, technology and learning. Coffey and Ashford-Rowe then present a case study description of an ePortfolio initiative at an Australian university. The next two papers have social media as a central focus. Hamid, Waycott, Kurnia and Chang present a study that investigates how lecturers integrate social technologies into their teaching, while Rambe and Ng'Ambi explore academic relations on Facebook. Thurlings and her colleagues present an investigation of feedback and social presence in online environments, while the paper by Chen outlines a study that investigates how an adaptive scaffolding system can support and promote student performance. The final paper in this issue deals with a perennial topic in educational technology and higher education - collaboration - with $\mathrm{Wu}$, Hwang and Kuo presenting an evaluation of a web-based collaborative learning system: Collab-Analyzer.

Barney Dalgarno, Gregor Kennedy and Sue Bennett

Lead Editors Australasian Journal of Education Technology 